\title{
Developing capacity for natural hazard management using an active learning approach and web-based geographical information
}

\author{
A. Kos \\ Geological Institute, Swiss Federal Institute of Technology, ETH Zurich, Switzerland \\ Received: 7 October 2008 - Revised: 22 December 2008 - Accepted: 30 December 2008 - Published: 6 February 2009
}

\begin{abstract}
A learning environment for university students using active learning in the field of natural hazard management is described. Students study a suite of hazard case studies that include earthquake, flood, debris flow, rock fall, snow avalanche, and landslide within a virtual Alpine valley, which has been constructed using a web-based geographical information system. Through a series of tasks carried out in collaborative workshops, students create structure and meaning from heterogeneous and disparate data and information in order to define and solve relevant problems presented within a natural hazard scenario.
\end{abstract}

\section{Introduction}

\section{Framework for capacity development in natural hazards}

The use of knowledge, innovation and education was identified as a key priority area for building a culture of safety and resilience in the United Nations International Strategy for Disaster Reduction (UNISDR), Hyogo Framework for Action 2005-2015 (HFA, 2005). Using the HFA as a backdrop for advocating knowledge, innovation and education in risk reduction, we focus the context of this paper on the higher education sector. A learning environment using webbased geographical information for University students to learn about natural hazard management has been developed as a project funded by the Swiss Federal Government, Swiss Virtual Campus consolidation program 2004-2007 (SVC, 2008a). As part of a collaborative project between ETH Zurich, EPF Lausanne, and the University of Bern, an entry level course specifically dedicated to developing introductory skills in dealing with Alpine natural hazards in Swiss institutes of higher education was developed. The project

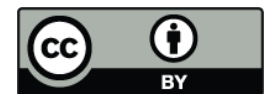

Correspondence to: A. Kos

(kos@erdw.ethz.ch)
(e-SCENARIO: scenario-based problem solving in natural hazard management) is currently implemented as a curriculum embedded course at ETH Zurich and the University of Bern.

E-SCENARIO builds upon the knowledge-level platform NAHRIS, dealing with natural hazards and risk (NAHRIS, 2008), which was a former project completed during the Swiss Virtual Campus impulse program 2000-2003 (SVC, 2008b). Following the taxonomy of Bloom (1956), the conceptual relationship between the levels of the learning goals between the two projects is shown in Fig. 1.

\section{An active learning approach to capacity development}

The e-SCENARIO was constructed around an active learning approach. Although this section is not intended as an exhaustive review of active learning, several of the salient issues are reviewed. Active learning is discussed by Lorenzen (2001), McConnell (1996), and Seeler et al. (1994) with respect to specific disciplines, such as computer science, and medicine, but perhaps the most relevant review for this paper is given by Prince (2004), concerning engineering sciences. Sokoloff and Thornton (1997), Ebert-May and Allred (1997), and Schank (1994) also discuss the subject specifically with respect to the use of multimedia and applied lecturing techniques. What is active learning? Active learning essentially means that students are actively engaged in dealing with meaningful problems that ideally relate to the real world, and during the process, they are thinking about what they are doing (Bonwell and Eison, 1991). Therefore, one of the central issues in active learning concerns the promotion of student engagement in the classroom (Prince, 2004). Prince points out however that simply introducing activities to classroom doesn't necessarily capture important components of active learning. In this respect, Wiggins and McTighe (1998) highlight that well designed activities contribute to developing a deep understanding of the key concepts and ideas to be learned.

Published by Copernicus Publications on behalf of the European Geosciences Union. 


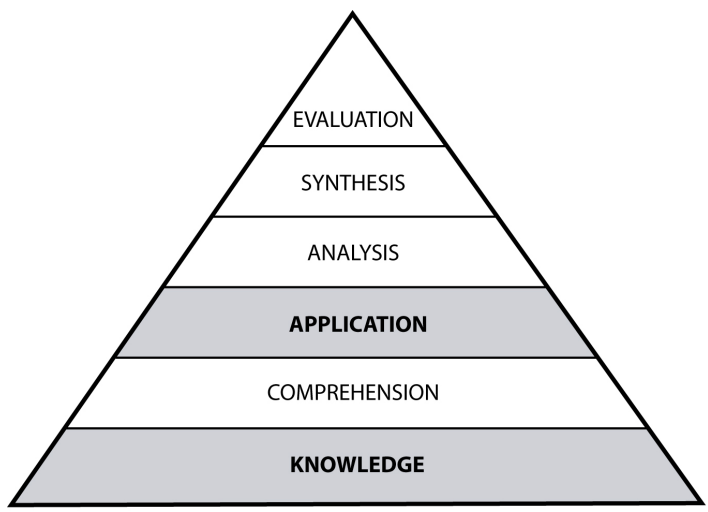

Bloom's Hierarchy

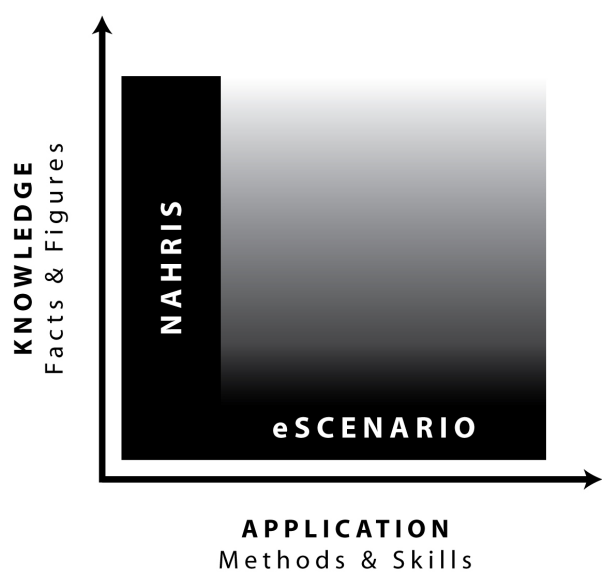

Fig. 1. Conceptual relationship of the learning levels (after Bloom, 1956) between the "knowledge" focused SVC project NAHRIS and the "application" oriented e-SCENARIO project.

In what ways can students become deeply engaged in learning? Two of the most commonly used approaches involve collaborative and problem-solving methodologies. With respect to collaborative learning, Dillenbourg (1999) discusses the difficulty in establishing a uniform definition of the term. A simple, albeit unsatisfactory definition states, "... it is a situation in which two or more people learn or attempt to learn something together" (Dillenbourg, 1999). This definition may also be extended to include the attainment of common goals (CQU, 2008). In a collaborative learning environment, learners engage in a process of interaction and negotiation with fellow students (in some circumstances with tutors and lecturers), where they share in the activity of problem solving (Dillenbourg, 1999; Kanselar et al., 2001). The measurable outcomes are the attainment and creation of new knowledge, as well as increased performance in problem solving (Dillenbourg, 1999).

Strongly coupled to the concept of collaborative learning, problem solving, is shown to be an effective way for students to learn (Mayer, 1993), and is described in several instructional models (Collins et al., 1989; Barrows, 1992; Finkle and Torp, 1995; Savery and Duffy, 2001). Problem-based learning (PBL) appears commonly in the literature although different strategies are used for its implementation. Savery and Duffy (2001) outline several of the main elements based on Barrows (1992) model of PBL, which are relevant to the topic of this paper. They are briefly summarized as:

- Primary concepts and principles of the content domain, that the students must learn, need to be identified.

- Problems must relate to the real world.

- Students must have ownership of the problem(s).

- Data associated with the analysis of the problem should highlight critical factors of the case. In other words, that the data presented to the students is specifically focused on a single desired outcome.

- Tutors and lecturers adopt the role of facilitator. Their main task is to ask questions that stimulate high-order thinking about the problem and challenge the learner's thinking.

\section{Course objectives}

The overall objectives of the e-SCENARIO course are to: 1) Build awareness of the engineering and science-based approaches to assessing and managing natural hazards; 2) Develop knowledge and skills in hazard assessment; and 3) Develop an understanding of the issues relevant for managing natural hazards. However, there are also distinct didactic objectives worth mentioning that are relevant to areas outside the higher education sector. They include the development of competencies in self-directed learning coupled with abilities to recognize and solve relevant problems, both individually and in groups. The latter are increasingly called upon in professional organizations and consultancies as well as postgraduate study programs, such as those at Masters and Doctorate levels.

The project has been embedded into University-level curriculum and is primarily focused at third year Bachelor students in natural science and engineering (e.g. Earth Science, Environmental and Forest Engineering, Environmental Science, etc.), who have little or no background in the natural hazards domain. As alluded to earlier, the level of the course is also appropriate for postgraduate students, and the technology-supported, active learning approach described in this paper is relevant to organizations in both the public and private sectors (e.g. NGO's, government departments, etc.), where risk reduction, capacity development activities are undertaken. 


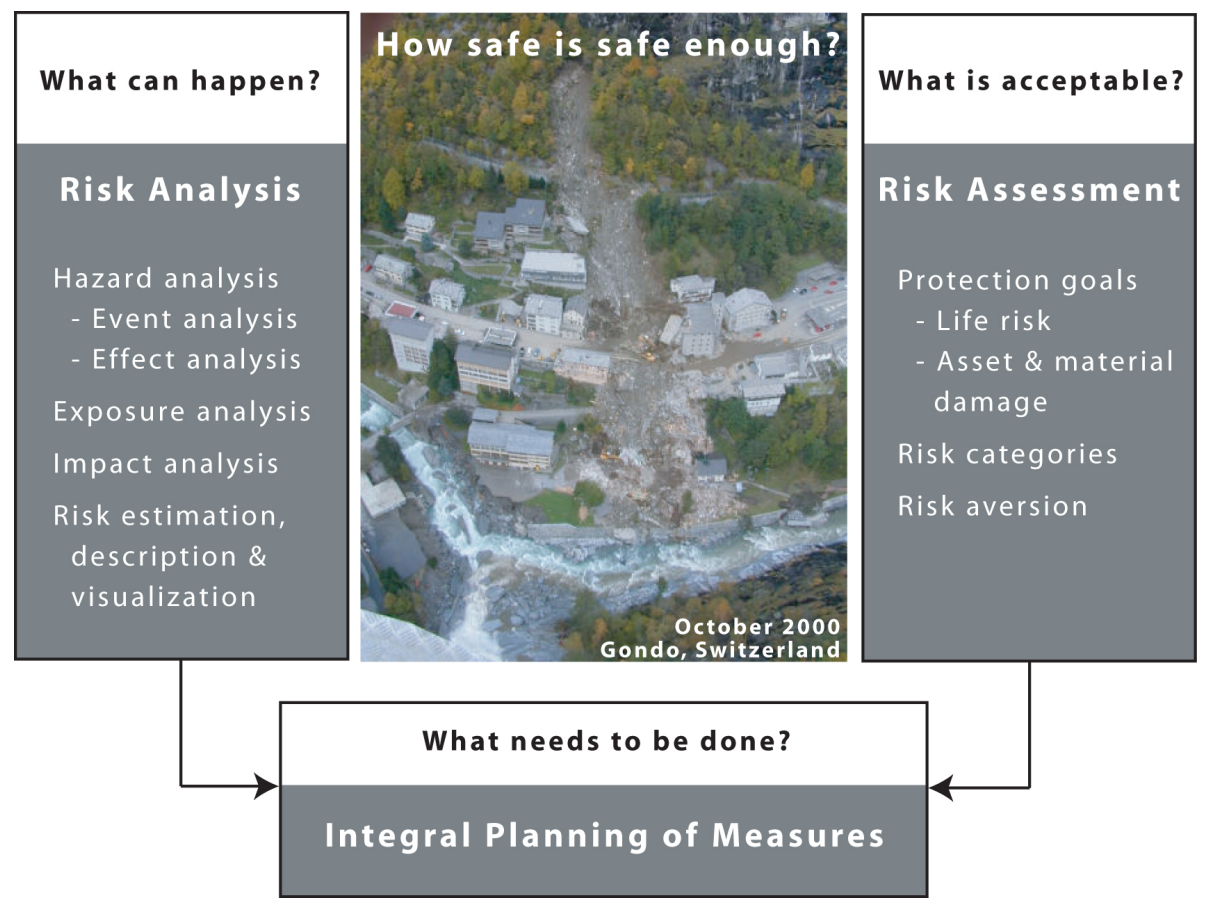

Fig. 2. Concept of risk developed by the Swiss National Platform for Natural Hazards-PLANAT (Ammann, 2006, modified after Schweizerische Armee, 1990).

The course is based upon the risk concept developed by the Swiss National Platform for Natural Hazards (PLANAT), and although the concept was originally intended for technical risks, Ammann (2006) outlines its relevancy to natural hazards. The risk concept (Fig. 2) is exemplified by three key questions: 1) What can happen; 2) What is acceptable; and 3) What needs to be done. The risk concept forms the basis of an integral risk management approach that has a direct relationship to different learning phases described in later sections of this paper. Those relationships are illustrated in Fig. 3.

\section{Learning objectives}

The main learning phases and assessment activities are summarized in Table 1 in terms of their purpose, learning objectives (e.g. the skills students need to demonstrate) and the teaching and learning approach taken. In Table 1, the level of learning that students are expected to reach has been associated to the taxonomy of Bloom (1956), thereby providing a framework in which high level learning objectives can be defined. Learning phases (e.g. 1-5 in Table 1) and the associated assessment tasks represent a progressive increase in the level of learning goals that the students reach during the course. They are described as the following: 1) Acquiring knowledge of hazardous natural processes (i.e. knowledge); 2) Understanding knowledge within specific hazard contexts (i.e. comprehension); 3) Applying methods for the assess-

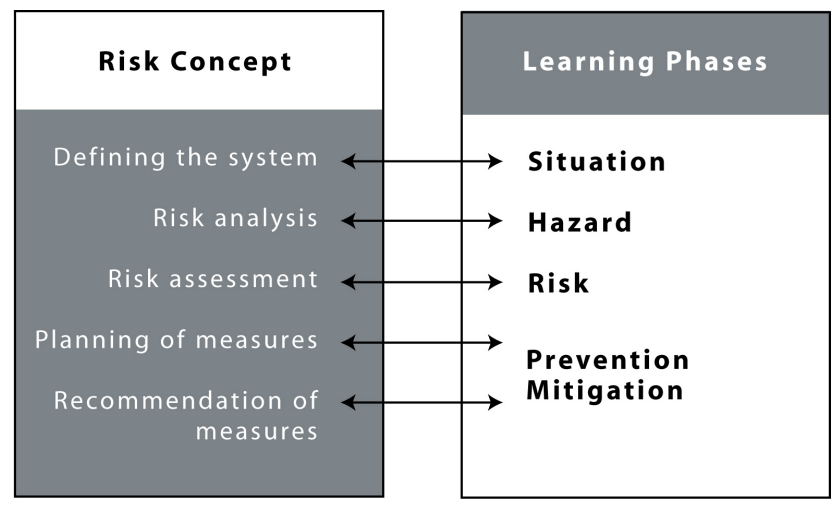

Fig. 3. The Swiss risk concept in relation to learning phases in eSCENARIO (modified after Ammann (2006).

ment of selected natural hazards (i.e. application); 4) Organizing the component parts of the hazard assessments into a meaningful structure through the preparation of reports (i.e. analysis); 5) Bringing together the results of risk analysis and the pre- and post implementation of mitigation measures to create a new context for dealing with risk (i.e. synthesis); and 6) Make judgments and conclusions concerning different prevention and mitigation measures based on the results of different student groups (i.e. evaluation). 
Table 1. Summary of learning phases with respect to purpose, learning goals and teaching/learning approach. The areas delineated by a hatched line indicate the main assessment tasks. (Large group $=6$ students, medium group $=4$ students, small group $=2$ students).

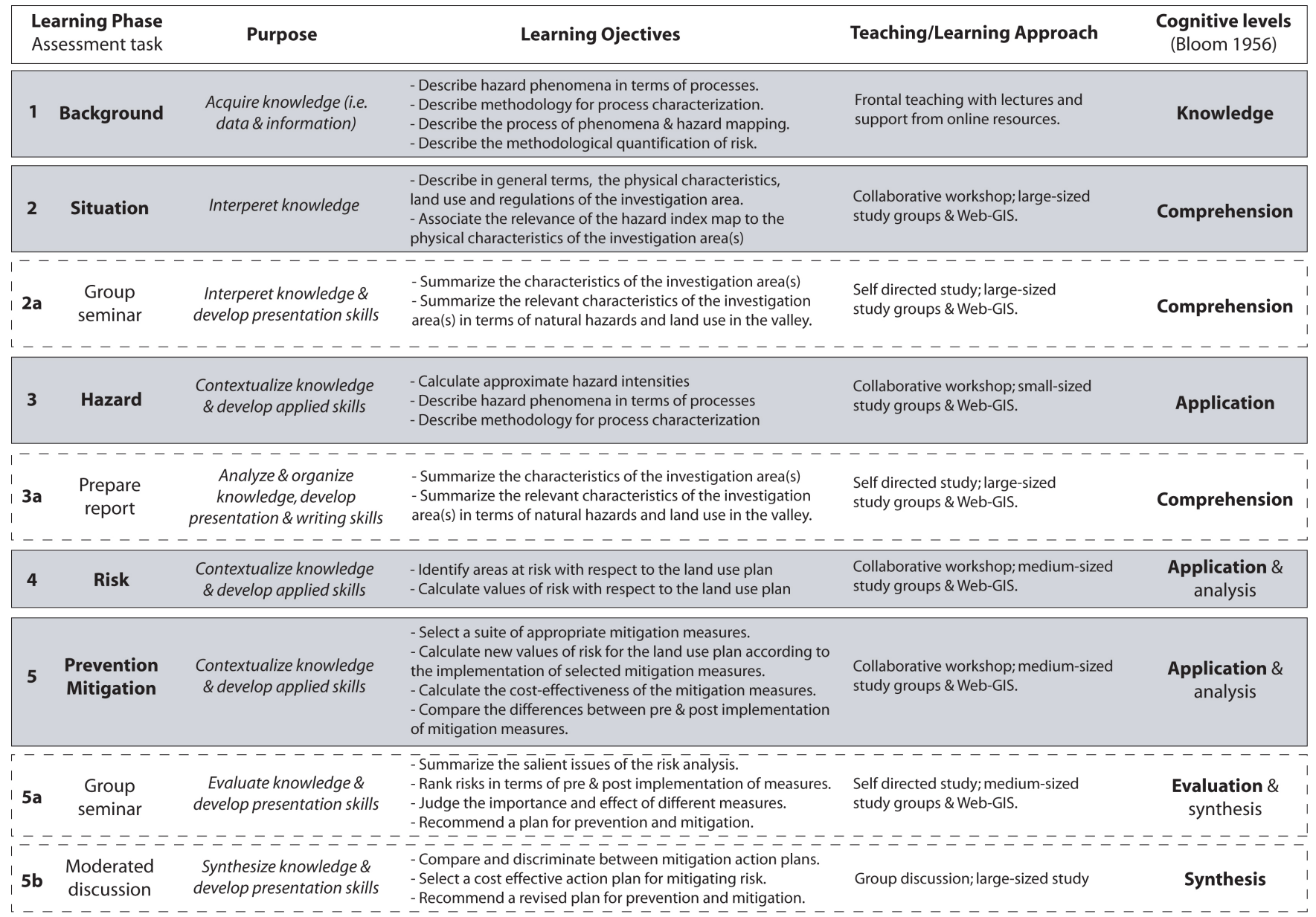

\section{Active learning and the role of students, tutors and lecturers}

The role of the tutors and lecturers is essentially that of a guide. The only exception to this is during the delivery of lectures, where the role of lecturer is somewhat traditional. However in this context, it incorporates the role of moderator particularly during the facilitation of classroom assessment tasks. In the workshops on the other hand, the key role of tutors and lecturers is to facilitate the asking of questions related to the workshop tasks. Secondarily, they provide the necessary support to students when it is either called upon, or observed that problems or difficulties are being experienced.

The role of students as learners is to actively engage in creating structure from disparate sources of data and information, solve problems and create new knowledge. In problem solving, the students: 1) Define the problems; 2) Decide what tasks and parameters are needed; 3 ) Analyze the problem; 4) Propose a solution or response; and 5) Evaluate the solution or response. As mentioned earlier, students work in groups to achieve common goals but also they bring together their own unique experiences and background knowledge, because students come from a variety of disciplines (e.g. Geography, Earth Science, Environmental Engineering, and Forest Engineering).

\section{Features of the Web-GIS learning environment}

The Web-GIS environment (i.e. Web Geographical Information System) was specifically designed to support the learning process and make otherwise cumbersome and timeconsuming tasks such as comparing map layers, drawing cross-sections, making measurements more efficient for students. The main features of the GIS system are illustrated in Fig. 5. They consist of: 1) Global navigation controls that correspond to three main learning phases; 2) Map viewing area; 3) Tools for layer navigation, visualization and 


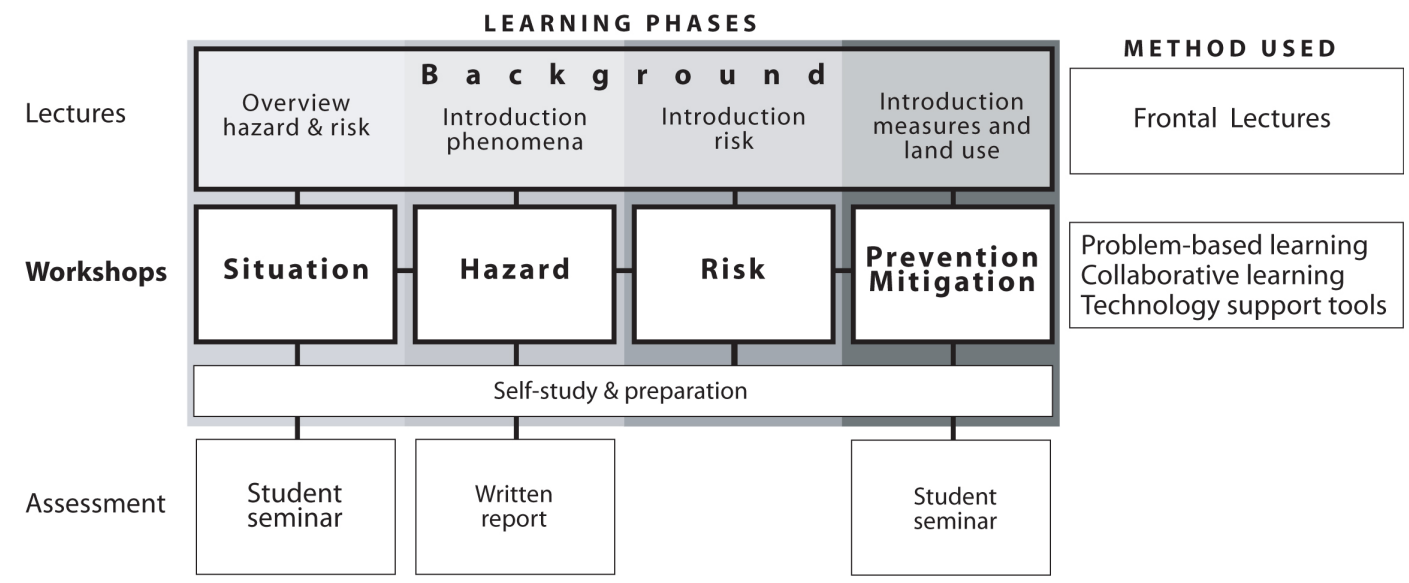

Fig. 4. Learning model of the e-SCENARIO learning environment.

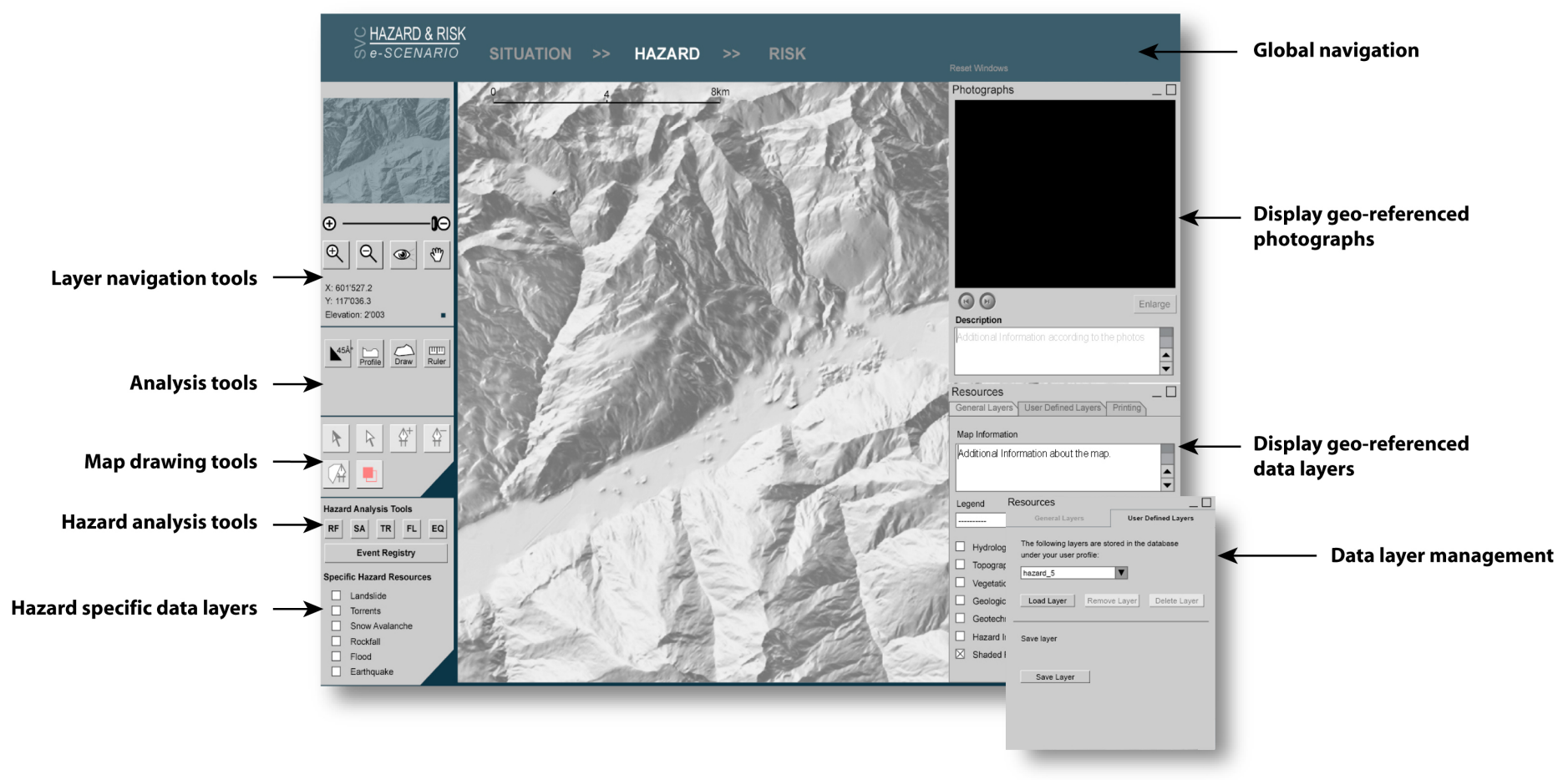

Fig. 5. Web-GIS interface highlighting specific features used in the learning process.

manipulation; 5) Tools for drawing basic (hazard) maps; 5) Print function to PDF format; 6) Display of geo-referenced photographs; and 7) Management tools for user defined data layers.

The use of the Web GIS is integrated with the collaborative workshops through it's design. For example global geospatial data (lower right panel) that is used in all workshops is accessed at a different location to that of geospatial data for particular workshops, such as situation, hazard and risk workshops, respectively (lower left panel). Virtual excursions are supported for each of the hazard workshops through the display of geo-referenced photographs (top right panel). Although not a part of the Web-GIS, the I-view 3$\mathrm{D}$ viewer, (IVS 3-D 2008) is used in combination with the GIS for visualizing high resolution orthoimages draped upon a digital terrain model (DTM).

From a technical standpoint, the GIS is a fully functional prototype, built upon a variety of open source technologies, which includes scalable vector graphics (SVG), a PostGRE SQL database with geospatial extensions, UMN map server (University of Minnesota Map Server) and PHP server scripts (see Fig. 6). 


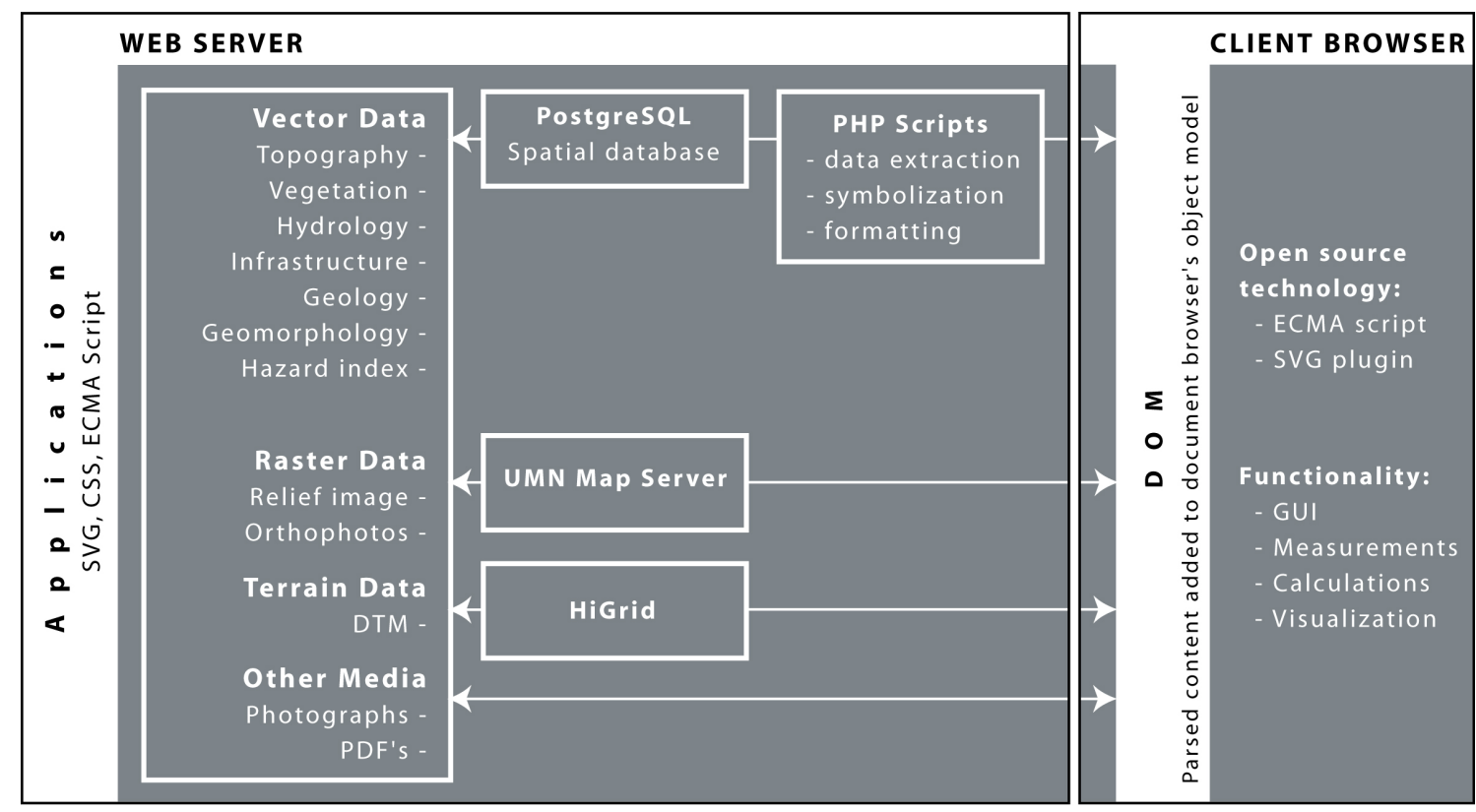

Fig. 6. Web-GIS server/client architecture (modified after Flüeler et al., 2006).

\section{Implementation of collaborative workshops}

\subsection{The learning environment}

The e-SCENARIO learning environment is built within framework consisting of four main learning phases (see Fig. 4). Each of the learning phases combine frontal lectures, collaborative workshops that integrated technology support tools (e.g. Web-GIS, simulation tools, and basic 3-D visualization) and assessment activities consist of writing reports and delivering seminar presentations that incorporate moderated group discussions.

The learning environment follows a blended or a mixed learning approach (Oliver and Trigwell, 2005), and is similar to the model of Kerres and De Witt (2003), where the learning environment is characterized by a combination of didactic method and delivery.

Frontal lectures provide specific thematic knowledge, which is directly applied in the workshops that follow. Most lectures are designed interactively, and seek to engage student participation through a variety of short-duration classroom assessment techniques (e.g. see Angelo and Cross, 1993). In the collaborative workshops, students work in groups to achieve common goals (group sizes vary according to the workshop thematic, and are given in Table 1). They are assessed in their respective groups, in the form of seminars (with active participation in moderated discussion), and preparation of reports. The main learning phases are described in the following sections.

\subsection{Situation}

Situation analysis is the first of a series of collaborative workshops that introduces the students to the virtual Alpine valley. The premise for undertaking hazard and risk investigations is briefly summarized in the following text:

"The communities in the Tooma section of the Potamos Valley have decided to expand the tourist potential of the region by developing a new ski resort, amongst other infrastructure.

A town plan has been made, however to be compliant with state and federal regulations an assessment of the proposed scheme with respect to natural hazards needs to be completed."

The main goal of the workshop is to provide a description of the virtual Alpine valley (e.g. geology, geomorphology, physiography, vegetation, climate, land use, and relevant regulations pertaining to natural hazards)

with respect to the distribution and occurrence of natural hazards shown on a generalized hazard index map. The students present their results in a seminar at the conclusion of the workshop and an accompanying written report acts as a reference document for the workshops that follow. For example, a description of climatic data such as rain and snowfall in the valley is used as reference material (i.e. hydrological input parameters) for the flood and debris flow workshops that are completed at a later date. 


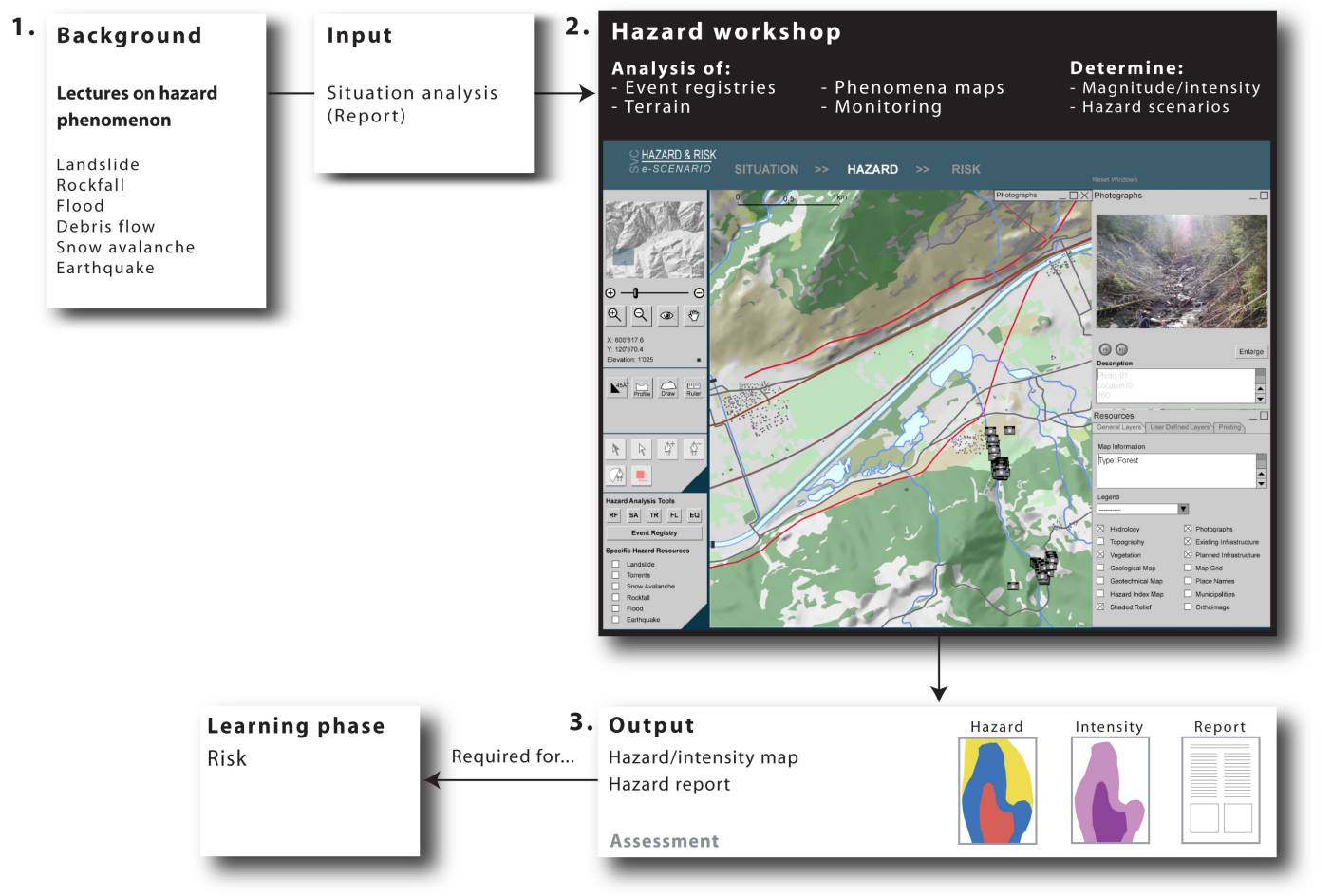

Fig. 7. Work flow diagram for the hazard analysis learning phase.

\subsection{Hazard}

The hazard learning phase consists of a series of six workshops, respectively dealing with flood, landslide, rock fall, debris flow, earthquake, and snow avalanche hazards. The conceptual workflow for hazard analysis is illustrated in Fig. 7, where students seek to answer the fundamental question "What can happen?" (see Fig. 2).

The entry point to the hazard workshop consists of two preparatory components. The first (number 1 in Fig. 7) is the completion of the situation analysis workshop. The second activity, (number 2 in Fig. 7) is the introductory lecture, which provides essential background to the hazard phenomena being studied. Additional background knowledge is gained through self study activities using learning units contained in the information platform NAHRIS.

A basic framework or guide for investigation is provided to help orient the students; however it is up to them to formulate their own detailed investigation tasks, based on their identification (and analysis) of potentially hazardous situations. Investigations for each hazard phenomena include: 1) A description of relevant features in the terrain; 2) Analysis of the event history; 3) Determination of hydrological characteristics of the catchment (where relevant); 4) Characterization of phenomena (i.e. interpretation of phenomena maps); 4) Formulation of hazard scenarios; 5) Calculation of intensity parameters; and 6) Creation of hazard and/or intensity maps.
The Web-GIS plays a central role in the analytical process by providing support for the visualization and manipulation of geospatial data and the production of hazard and/or intensity maps.

The main assessment task is the production of hazard and intensity maps with an accompanying hazard report, which includes a description, interpretation and discussion of the defined problem(s), investigations made and assessment outcomes.

\subsection{Risk}

The risk learning phase is concerned with the question "What is acceptable?" (see Fig. 2). In answering this question, students undertake a quantitative risk assessment following the methodology of Borter (1999a, b), where risk is characterized by potential damage, or in other words potential direct consequences, expressed in terms of monetary value and expected deaths per year and event. The method, referred to here as the FOEN method, consists of three distinct stages (see Fig. 8), that focus on the identification of: 1) Protection deficits and priorities; 2) Object and collective risk for groups of objects and areas of land use; and 3) Object and individual risk for individual objects that are occupied by people or serve special purposes e.g. schools and hospitals. For further details about the three stages of risk analysis the reader is referred to Borter (1999a). 


\begin{tabular}{|c|c|c|}
\hline \multicolumn{3}{|c|}{$S$ a f e t y P r o b I e $\mathrm{m}$} \\
\hline $\begin{array}{r}R \text { i s } k \\
\text { Semi-quantitative } \\
\text { Risk Analysis }\end{array}$ & $\begin{aligned} \text { a I y s is } & M \text { e } \\
& \\
& \text { Quan } \\
& \text { Risk }\end{aligned}$ & $\begin{array}{l}h \circ d \\
\text { tative } \\
\text { alysis }\end{array}$ \\
\hline $\begin{array}{l}\text { Identify: } \\
\text { Protection deficits } \\
\text { Conflict areas } \\
\text { Define: } \\
\text { Protection goals }\end{array}$ & $\begin{array}{l}\text { Identify: } \\
\text { Object risk } \\
\text { Collective risk } \\
\text { based upon groups of } \\
\text { objects i.e. general } \\
\text { land use patterns. }\end{array}$ & $\begin{array}{l}\text { Identify: } \\
\text { Object risk } \\
\text { Individual risk } \\
\text { based upon individual } \\
\text { objects e.g. buildings } \\
\text { and section of } \\
\text { roadway, and special } \\
\text { objects e.g. schools, } \\
\text { hospitals }\end{array}$ \\
\hline $\begin{array}{c}\text { Risk Analysis } \\
\text { Stage } 1\end{array}$ & $\begin{array}{c}\text { Risk Analysis } \\
\text { Stage } 2\end{array}$ & $\begin{array}{c}\text { Risk Analysis } \\
\text { Stage } \mathbf{3}\end{array}$ \\
\hline 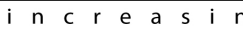 & $d$ e $p \quad t h \quad o f$ & a $n$ a \\
\hline $\begin{array}{l}\text { Basis for: } \\
\text { Assignment of priorities } \\
\text { in the endangered or } \\
\text { investigation areas. } \\
\text { Consideration of } \\
\text { danger areas in town } \\
\text { and emergency } \\
\text { planning } \\
\text { Planning of measures }\end{array}$ & $\begin{array}{l}\text { Basis for: } \\
\text { Setting priorities in Risk } \\
\text { Cost effectiveness/cost } \\
\text { Town and emergency pl } \\
\text { Insurance purposes } \\
\text { Property leasing }\end{array}$ & $\begin{array}{l}\text { lanagement } \\
\text { enefit analysis } \\
\text { nning }\end{array}$ \\
\hline
\end{tabular}

Fig. 8. Overview of the three-stage risk analysis method (modified after Borter (1999a)

Currently, all three stages of the FOEN method are implemented within two risk scenarios, relating to debris flow and snow avalanche hazards respectively. Both scenarios use hazard or intensity maps as overlays produced during the hazard learning phase to determine areas with protection deficits and to quantify potential damage. The debris flow risk scenario, described in more detail below, is analyzed using the Stage Two approach, where risk is quantified according to the spatial characteristics of different land use zones (e.g. purpose of the zone and the density of buildings contained within). The snow avalanche risk scenario on the other hand is analyzed in more detail using the Stage Three approach. In this case, a large hotel of wooden construction, with a glass fronted restaurant on the ground floor is planned to be built in a ski resort area potentially at risk from snow avalanche. The primary focus of the analysis is the quantification of the potential loss of life; however this scenario will not be described in detail in this paper.

With respect to the debris flow risk scenario, the workshop commences with students working in groups of 3-4 undertaking activities designed to familiarize themselves with a town located on a large debris fan endangered by debris flows (see Fig. 9). Protection deficits are identified through analysis of hazard/intensity maps, existing and planned infrastructure, land use, and various documents that describe local industries, tourism, and cultural heritage. In addition, state- ments from key stakeholders, in the form of extracts from municipal meetings discussing a proposed 10 year strategic plan, are also evaluated.

Once critical areas have been identified, different land use zones are analyzed with respect to medium and strong intensity zones indicated by the hazard or intensity map for 30 , 100 and 300 year scenarios. Damage potential for different types of land use is the product of: 1) Reciprocal of the return period scenario (e.g. 30, 100 or 300 year); 2) Values for specific damage potential (derived from statistical data) given in Borter (1999b); and 3) Density of buildings for a particular land use zone. The damage potential for a specific land use zone is therefore expressed as a monetary value per unit area. Attributes for buildings located in critical areas, such as purpose and construction type, are included qualitatively in the risk analysis.

The potential number of deaths is quantified in a similar way to potential damage described above, except that an additional term is introduced accounting for the occupation rate for a given land use area. Therefore potential death is a product of the following: 1) Reciprocal of the return period scenario in question; 2) Presence probability of people being in the land use zone (e.g. estimated presence time in hours divided by 24); 3) Statistically derived values, given in Borter (1999b), for number of deaths dependant upon the intensity and type of hazard; and 4) Density of buildings occupied by people within a particular land use zone.

The main outcomes of the risk workshop are two risk matrices that provide calculated values for: 1) Damage potential of infrastructure according to land use zones (e.g. per event and per year); and 2) Potential deaths (e.g. number of deaths per event, per year and associated monetary cost).

\subsection{Prevention and mitigation}

The prevention and mitigation learning phase deals with the question "What needs to be done?" (Fig. 2), particularly with respect to reducing risk as calculated in the preceding risk workshop. In exploring solutions for reducing risk, students evaluate a suite of active and passive measures for their effect in reducing damage potential and loss of life. This is done through a simple cost-benefit approach using the following criteria: 1) Initial cost of investment; 2) Cost of ongoing maintenance; and 3) Duration or life span of the measure.

The outcome of the workshop is an extended risk matrix, which comparatively demonstrates how a selected suite of measures reduces the overall risk. The results are presented in a group seminar and submission of a summary report. Since different groups evaluate different sets of measures, a moderated discussion is used at the conclusion of the seminar to synthesize results from different groups. The aim is to establish an optimum risk reduction strategy. The seminar presentation, summary report and participation in the moderated discussion form a major component of course assessment (Table 1). 
1. Input

Situation analysis (Report)

Hazard analysis (Report)

Hazard/Intensity map

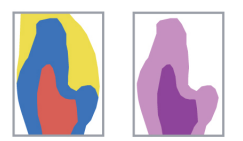

\section{Risk workshop}

Analysis of:

- Affected communities

- Land use (infrastructure) - Type of construction

Determine:

- Protection goals

- Potential damage

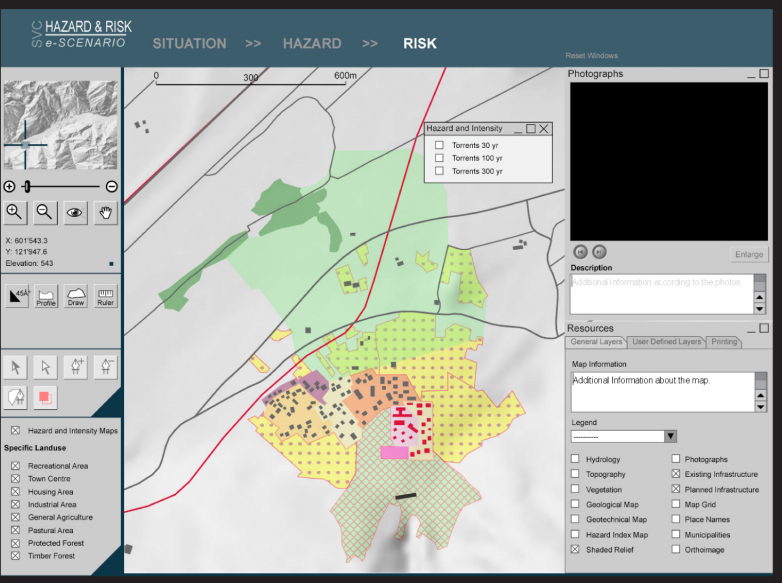

Learning phase

Prevention \&

Mitigation

3. Output

Informal report:

Description and

quantification of risk

Fig. 9. Work flow diagram for the risk analysis learning phase.
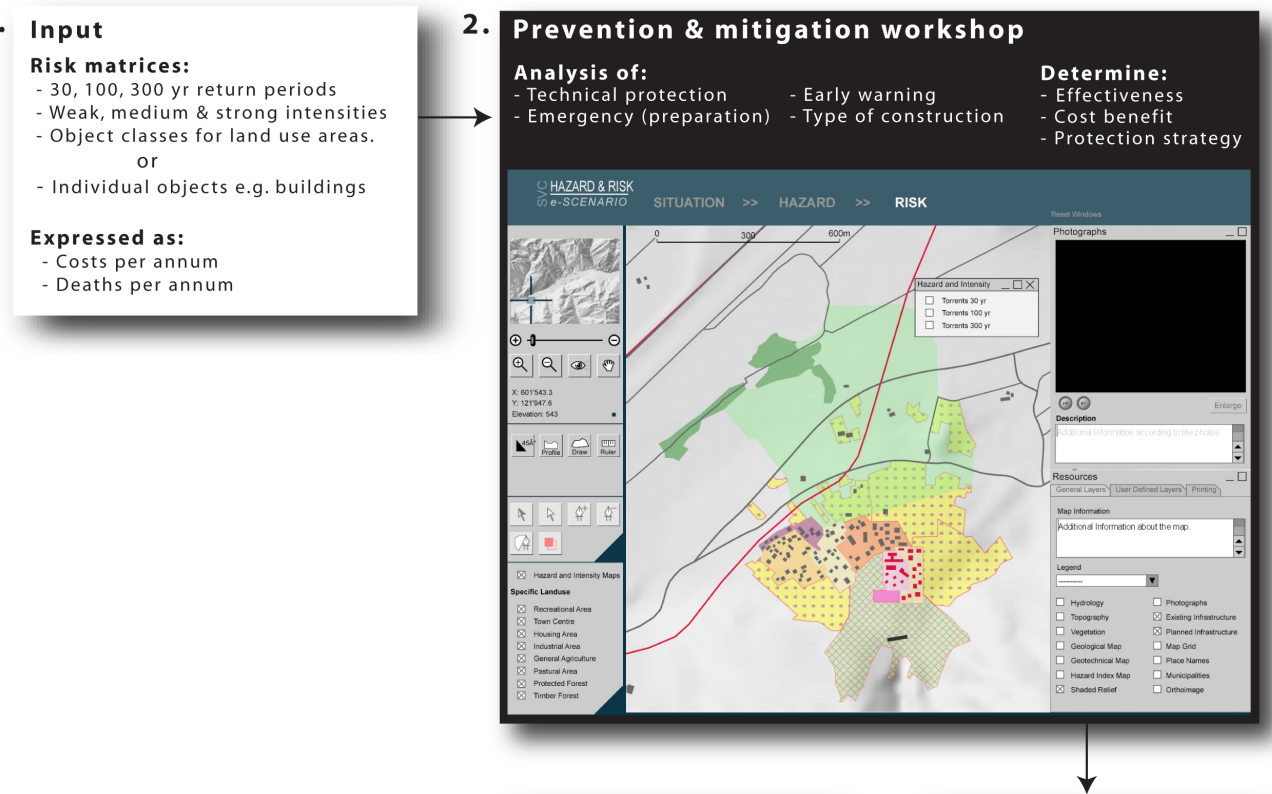

4. Moderated discussion

3. Seminar presentations "Prevention/mitigation Strategy"

Assessment Assessment

Fig. 10. Work flow diagram for the prevention and mitigation learning phase. 


\section{Course feedback}

The course has been offered since 2007 and has been evaluated qualitatively each semester using informal debriefing and observation. A focus group consisting of 5-6 students (representing an average class size of 35) was used to elicit feedback for the following criteria: 1) Level of difficulty for workshop tasks; 2) Workload for different learning phases; 3) Overall satisfaction; and 4) Tool functionality and ease of use. Open comments were also elicited from various students. The salient points are summarized as the following: Approximately $30 \%$ of students dropped the course due to the high workload. The remaining students were greatly challenged, some experiencing initial frustration with the workshop problems, but later becoming fully engaged when they understood what was expected of them. Most students had difficulty with the ongoing assessment that took place over the semester. The group work was well accepted and appeared to increase the quality of submitted work (e.g. hazard reports). Generally, there was great interest in the hands-on approach to the subject matter, because the tasks reflected those typically done in a real hazard and risk investigation.

\section{Conclusions}

A learning environment using an active approach to learning about natural hazard management has been described. Using a Web-GIS platform as a central element in the learning process, students study a suite of hazard scenarios that include earthquake, flood, debris flow, rock fall, and landslide within a virtual geographical setting (e.g. a virtual Alpine valley). Working within a defined framework and guided by tutors and lecturers, students define and undertake a series of investigation tasks within collaborative workshops. They create structure and meaning from heterogeneous and disparate data and information in order to define problems, create new knowledge, and propose solutions in reducing risk for a natural hazard scenario.

Acknowledgements. Special acknowledgement and thanks go to the e-SCENARIO development team for their commitment in successfully developing and implementing the project described in this paper. The team consisted of S. Loew, H. Kienholz, B. Krummenacher, O. Muff, R. Stopper, S. Demamels, J. Neumann-Williams, H. Gosteli, F. Schmid, T. Studi, A. Musy, C. Schenk, and C. Picouet. The project was co-funded by the Swiss Federal Government's "Swiss Virtual Campus" programme, ETH Zürich (Fonds FILEP), EPF Lausanne and the University of Bern (Project number P-3-023). The author is greatly appreciative and thankful for the many enlightening discussions with Terry Jeggle and Joanne Burke (UNISDR CADRI) that in many ways helped form ideas about new ways to engage students in learning about natural hazards. Many thanks also go to the NHESS reviewers for providing positive feedback, and J. Moore for the final corrections to the manuscript.

Edited by: M.-C. Llasat

Reviewed by: K. Thuro and another anonymous referee

\section{References}

Ammann, W. J.: Risk Concept, Integral Risk Management and Risk Governance, in: Risk21-Coping with Risks due to Natural Hazards in the 21st Century, edited by: Ammann, W. J., Dannenmann, S., and Vulliet, L., Taylor \& Francis Group, London, UK, 3-23, 2006.

Angelo, T. A. and Cross, K. P.: Classroom Assessment Techniques, San Francisco, Jossey-Bass, 2nd edn., 119-180, 1993.

Barrows, H.: The Tutorial Process. Springfield, IL: Southern Illinois University School of Medicine, 1992.

Bloom, B. S.: Taxonomy of Educational Objectives, the Classification of Educational Goals, Handbook I, Longmann, New York, 1956.

Bonwell, C. C. and Eison, J.: Active Learning: Creating Excitement in the Classroom, ASHE ERIC Higher Education Report No. 1, George Washington University, Washington DC, USA, 1991.

Borter, P.: Risikoanalyse bei gravitativen Naturegefahren - Methode, Umweltmaterialien 107/I, BUWAL, Bern, Switzerland, 1999a.

Borter, P.: Risikoanalyse bei gravitativen Naturegefahren - Fallbeispiele und Daten, Umweltmaterialien 107/II, BUWAL, Bern, Switzerland, 1999b.

Collins, A., Brown, J. S., and Newman, S. E.: Cognitive Apprenticeship: Teaching the Crafts of Reading, Writing, and Mathematics, in: Knowing, Learning, and Instruction: Essays in honor of Robert GlaserResnick, edited by: Resnick, L. B., Hillsdale, N. J.: Lawrence Erlbaum Associates, 453-494, 1989.

CQU: http://clp.cqu.edu.au/glossary.htm, last access: 24 January 2008.

Dillenbourg, P.: What do you mean by Collaborative Learning?, in: Collaborative-learning: Cognitive and Computational Approaches, edited by: Dillenbourg, P., Oxford, Elsevier, 1-19, 1999a.

Ebert-May, D. and Allred, S.: Innovation in Large Lectures: Teaching for Active Learning, Bioscience, 47(9), 601-607, 1997

Finkle, S. L. and Torp, L. L.: Introductory documents, Available from the Center for Problem-Based Learning, Illinois Math and Science Academy, 1500 West Sullivan Road, Aurora, IL, USA, 60506-1000, 1995.

Flüeler, I., Iosifescu-Enescu, I. Neumann, A., and Hurni, L.: Cartographic SVG Applications as Risk Management and Communication Platforms, in: Proceedings of the Fourth International Conference on Geographic Information Science, Münster, Germany, 1-13, 2006.

HFA: Hyogo Framework for Action 2005-2015: Building the Resilience of Nations and Communities to Disasters, World Conference on Disaster Reduction, 18-22 January 2005, Kobe, Hyogo, Japan, 2005.

IVS 3-D: http://www.ivs3d.com/products/iview3d/, last access: 21 January 2008.

Kerres, M. and De Witt, C.: A Didactical Framework for the Design of Blended Learning Arrangements, J. Educ. Media, 28(2- 
3), 101-113, 2003.

Lorenzen, M.: Active Learning and Library Instruction, Illinois Libraries, 38(2), 19-24, 2001.

Mayer, R. E.: Problem-solving Principles, in: Instructional Message Design: Principles from Behavioral and Cognitive Sciences, edited by: Fleming, M. and Levie, W. H., NJ, Educational Technology Publications, Englewood Cliffs, 253-282, 1993.

Mc Connell, J. J.: Active learning and its use in Computer Science. SIGCSE Bulletin, 20(1), Special issue 52-54, 1996.

NAHRIS: http://www.nahris.ch/, last access: 18 January 2008.

Oliver, M. and Trigwell, K.: Can "Blended Learning" be Redeemed? E-Learning, 2(1), 17-26, 2005.

Prince, M.: Does Active Learning Work? A Review of the Research, J. Eng. Educ, 93(3), 223-231, 2004.

Savery, J. R. and Duffy, T. M.: Problem Based Learning: An Instructional Model and its Constructivist Framework, Center for Research on Learning and Technology, Indiana University, Technical Report No. 16-01, 6-8, 2001.
Schank, R.: Active Learning through Multimedia, IEEE Multimedia, Spring 1994, 1(1), 69-78, 1994.

Seeler, D. C., Turnwald, G. H., and Bull, K. S.: From Teaching to Learning, part III: Lectures and Approaches to Active Learning, J. Vet. Med. Educ., 21(1), 37-39, 1994.

Sokoloff, D. R. and Thornton, R. K.: Using Interactive Lecture Demonstrations to Create an Active Learning Environment, AIP Conference Proceedings, 399, 1061-1074, 1997.

SVC: http://www.virtualcampus.ch/, last access: 18 January 2008a.

SVC: http://www.virtualcampus.ch/display.php?lang=1\{\\&\}pid= 203, last access: 18 January 2008b.

Wiggins, G. and Mc Tighe, I.:Understanding by Design. Merrill Education/ASCD, College Textbook Series, ASCD, Alexandria, Virginia, USA, 1998. 